\title{
EFEKTIVITAS INTEGRASI MUSYAWARAH PERENCANAAN PEMBANGUNAN DESA DENGAN PROGRAM NASIONAL PEMBERDAYAAN MASYARAKAT MANDIRI PERDESAAN DI KABUPATEN BADUNG PROVINSI BALI
}

\author{
Ida Bagus Krisdeny Mahajaya ${ }^{1}$ \\ I Nyoman Mahaendra Yasa ${ }^{2}$ \\ Ni Nyoman Yuliarmi ${ }^{3}$ \\ ${ }^{1,2,3}$ Fakultas Ekonomi dan Bisnis Universitas Udayana (UNUD) Bali, Indonesia \\ Email.kmahajaya@mampu.or.id
}

\begin{abstract}
ABSTRAK
Tujuan penelitian ini untuk menganalisis (1) tingkat efektivitas integrasi program musyawarah perencanaan pembangunan desa dengan program nasional pemberdayaan masyarakat mandiri perdesaan di Kabupaten Badung Provinsi Bali; (2) pengaruh pelaksanaan integrasi program musyawarah perencanaan pembangunan desa dengan program nasional pemberdayaan masyarakat mandiri perdesaan terhadap pendapatan rumah tangga sasaran di Kabupaten Badung Provinsi Bali; (3) pengaruh pelaksanaan integrasi program musyawarah perencanaan pembangunan desa dengan program nasional pemberdayaan masyarakat mandiri perdesaan terhadap kesempatan kerja rumah tangga sasaran di Kabupaten Badung Provinsi Bali. Hasil penelitian menunjukkan (1) tingkat efektivitas integrasi program musyawarah perencanaan pembangunan desa dengan program nasional pemberdayaan masyarakat mandiri perdesaan di Kabupaten Badung Provinsi Bali sangat efektif dengan nilai pencapaian di atas 80 persen; (2) Pelaksanaan integrasi program musyawarah perencanaan pembangunan desa dengan program nasional pemberdayaan masyarakat mandiri perdesaan berpengaruh positif dan signifikan terhadap pendapatan rumah tangga sasaran di Kabupaten Badung Provinsi Bali; (3) Pelaksanaan integrasi program musyawarah perencanaan pembangunan desa dengan program nasional pemberdayaan masyarakat mandiri perdesaan berpengaruh positif dan signifikan terhadap kesempatan kerja bagi rumah tangga sasaran di Kabupaten Badung Provinsi Bali.
\end{abstract}

Kata Kunci: tingkat efektivitas, integrasi program, pendapatan rumah tangga, kesempatan kerja.

\begin{abstract}
This study to analyze (1) the effectiveness of the integration program rural development planning with community empowerment national program of rural self-sufficient in the Badung regency of Bali Province; (2) the effect of the implementation of the integration program rural development planning with the national community empowerment program in rural independently on household income target in the Badung regency of Bali Province; (3) the effect of the implementation of the integration program rural development planning with community empowerment national program on employment in rural independent target households in the Badung regency of Bali province. The results showed (1) the effectiveness of the integration program rural development planning with the national community empowerment program in rural independent in the Badung regency of Bali Province effective with the achievement of values above 80 percent; (2) The implementation of the integration program rural development planning with national community empowerment program in rural independent positive and significant impact on household income target in the Badung regency of Bali Province; (3) The implementation of the integration program rural development planning with national community empowerment program in rural independent positive and significant impact on employment for the target households in the Badung regency of Bali province.
\end{abstract}

Keywords: $\quad$ effectiveness level, integration program, rural household income, employment opportunities 


\section{PENDAHULUAN}

Musrenbang merupakan forum perencanaan pembangunan formal dari tingkatan yang diawali dari desa, kecamatan, kabupaten, provinsi sampai dengan nasional yang bertujuan mengsinkronisasi aspirasi masyarakat dalam perencanaan pembangunan pemerintah. Petunjuk teknis terhadap PNPM MP itu sendiri dikeluarkan oleh Ditjen Pemberdayaan Masyarakat Desa (PMD) yang berada di bawah Kementerian Dalam Negeri.

Program pemerintah PNPM MPd merupakan bentuk program yang digalakan pemerintah dalam menanggulangi kemiskinan dengan melibatkan masyarakat secara langsung dalam kegiatan program. Program PNPM MPd dirancang dengan melibatkan Musrembangdes guna memperoleh aspirasi masyarakat secara langsung, sehingga pelaksanaan program mencapai sasaran sesuai tujuannya.

Kabupaten Badung turut menerapkan kebijakan pemerintah, salah satunya kebijakan yang berkaitan dengan kesejahteraan masyarakat. Secara makro, kondisi kemiskinan di Kabupaten Badung menunjukan perkembangan yang cukup menggembirakan, namun secara mikro di Kabupaten Badung merupakan salah satu pusat perekonomian dan sebagai kota pariwisata tidak luput dari masalah kemiskinan yang tersebar di seluruh Kecamatan di Kabupaten Badung.

Upaya percepatan penanggulangan kemiskinan dimaksudkan tidak hanya untuk memperbaiki tingkat kesejahteraan masyarakat miskin hingga dapat melampaui atau minimal mendekati garis kemiskinan namun juga menjaga agar penduduk yang hampir miskin tidak jatuh ke bawah garis kemiskinan. Untuk itu 
diperlukan kategori rumah tangga berdasarkan katagori sangat miskin, miskin dan hampir miskin seperti dapat dilihat pada Tabel 1.

Tabel 1

RTS PerKabupaten/Kota di Provinsi Bali Tahun 2014

\begin{tabular}{clrrrrrrr}
\hline & & \multicolumn{7}{c}{ Jumlah RTS } \\
\cline { 3 - 8 } No & $\begin{array}{c}\text { Kabupaten/ } \\
\text { Kota }\end{array}$ & $\begin{array}{c}\text { Sangat } \\
\text { Miskin }\end{array}$ & $\begin{array}{c}\text { SM } \\
\mathbf{\%}\end{array}$ & Miskin & $\begin{array}{c}\text { M } \\
\text { \% }\end{array}$ & $\begin{array}{c}\text { Hampir } \\
\text { Miskin }\end{array}$ & $\begin{array}{c}\text { HM } \\
\text { \% }\end{array}$ & $\begin{array}{c}\text { Jumlah } \\
\text { RTS }\end{array}$ \\
\hline 1 & Jembrana & 4.331 & 5,96 & 4.412 & 6,07 & 4.411 & 6,97 & 13.154 \\
2 & Tabanan & 5.540 & 5,22 & 8.812 & 8,30 & 8.810 & 8,30 & 23.162 \\
3 & Badung & $\mathbf{3 . 0 8 9}$ & $\mathbf{2 , 1 7}$ & $\mathbf{5 . 1 1 7}$ & $\mathbf{3 , 5 9}$ & $\mathbf{5 . 1 1 7}$ & $\mathbf{3 , 5 9}$ & $\mathbf{1 3 . 3 2 3}$ \\
4 & Gianyar & 5.428 & 5,24 & 10.225 & 9,88 & 10.224 & 9,88 & 25.877 \\
5 & Klungkung & 2.663 & 6,10 & 4.391 & 10,06 & 4.391 & 7,40 & 11.445 \\
6 & Bangli & 2.401 & 4,33 & 5.218 & 9,41 & 6.293 & 9,41 & 55.473 \\
7 & Karangasem & 5.630 & 5,64 & 11.662 & 11,27 & 11.621 & 11,27 & 28.673 \\
8 & Buleleng & 8.422 & 4,87 & 21.481 & 12,41 & 21.481 & 12,41 & 51.384 \\
9 & Denpasar & 3.728 & 4,01 & 5.403 & 7,46 & 5.402 & 7,46 & 14.533 \\
\hline Provinsi Bali & 41.232 & 4,01 & 76.681 & 7,46 & 76.675 & 7,46 & 194.588 \\
\hline Sumber : Badan Pemberdayaan Masyarakat Desa (BPMD) Provinsi Bali, 2015 & &
\end{tabular}

Kabupaten Badung yang menyandang kabupaten terkaya di Provinsi Bali, dan merupakan salah satu pusat perekonomian dan sebagai kota Pariwisata tak lantas membuat Kabupaten Badung terlepas dari masalah kemiskinan. Lokasi Integrasi Musrenbangdes dengan PNPM MPd di Kabupaten Badung dengan masing-masing rumah tangga sasaran yang sangat rentan jatuh ke bawah garis kemiskinan. Dengan menggunakan pendekatan pengentasan kemiskinan dengan melibatkan masyarakat (Integrasi Musrenbangdes dengan PNPM MPd) dengan rumusan menyatukan perencanaan yang melibatkan masyarakat yang bersifat partisipatif, mendampingi masyarakat desa agar mampu memiliki program jangka menengah desa dan mengendalikan pelaksanan program pembangunan, sehingga sasaran program agar masyarakat tidak jatuh di bawah garis kemiskinan.

\section{Desain Penelitian}

Proses pembangunan secara keseluruhan menempatkan masyarakat sebagai inti dari pembangunan, yaitu sebagai subyek sekaligus obyek di 
Ida Bagus Krisdeny Mahajaya, I Nyoman Mahaendra Yasa, dan Ni Nyoman Yuliarmi. Efektivitas...

dalamnya. Integrasi Musrenbangdes dengan PNPM MPd dilakukan guna menjaring aspirasi masyarakat agar dapat menjadi masukan dalam pelaksanaan program pemerintah. Penggalian, pemenuhan dan pelaksanaan aspirasi semua pihak di tingkat desa yang berkualitas tentunya akan dapat meningkatkan pendapatan dan peluang kerja khususnya bagi masyarakat miskin.

Dalam pelaksanaan PNPM MPd, program yang digalakan pemerintah dalam menanggulangi kemiskinan dengan melibatkan masyarakat secara langsung dalam kegiatan program. Program PNPM MPd dirancang dengan melibatkan Musrembangdes guna memperoleh aspirasi masyarakat secara langsung, sehingga pelaksanaan program mencapai sasaran sesuai tujuannya. Upaya percepatan penanggulangan kemiskinan dimaksudkan tidak hanya untuk memperbaiki tingkat kesejahteraan masyarakat miskin hingga dapat melampaui atau minimal mendekati garis kemiskinan namun juga menjaga agar penduduk yang hampir miskin tidak jatuh ke bawah garis kemiskinan. Kerangka berpikir dalam penelitian ini digambarkan sebagai berikut: 


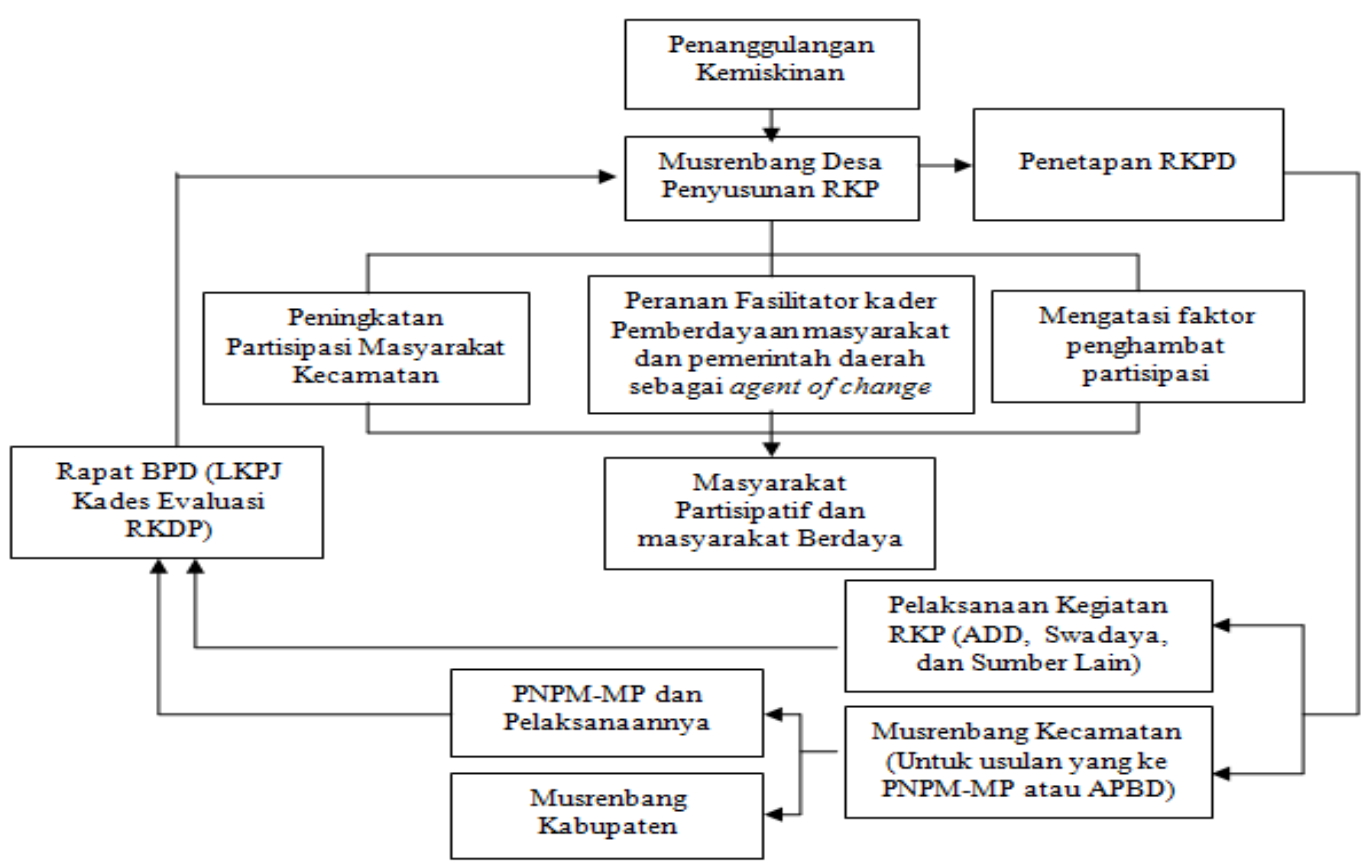

Gambar 1. Desain Penelitian

\section{Konsep Penelitian}

Kerangka konsep dalam penelitian ini dalam mengukur efektivitas integrasi Musrenbangdes dengan PNPM MPd disesuaikan dengan prinsip atau nilai dasar dari PNPM MPd yaitu melalui komponen-komponen:

1) Input (Perencanaan Program) adalah mengukur keterlibatan aktif masyarakat miskin dalam proses atau alur tahapan program dan pengawasannya dan perencanaan program yang berpihak dan tetap berorientasi kepada masyarakat miskin.

2) Proses (Pelaksanaan Program) adalah mengukur kemampuan dan ruang yang lebih luas kepada masyarakat dan lembaga di tingkat masyarakat untuk berperan aktif dalam mengelola pelaksanaan program secara mandiri dan bersama-sama pemerintah setempat dan kelompok peduli menanggulangi kemiskinan di wilayahnya. 
Ida Bagus Krisdeny Mahajaya, I Nyoman Mahaendra Yasa, dan Ni Nyoman Yuliarmi. Efektivitas...

3) Output (Pengawasan/Pengendalian) adalah mengukur masyarakat dapat melihat keterbukaan informasi proses pengambilan keputusan dan pertanggungjawaban pelaksanaan program.

4) Outcome (Dampak Program bagi Masyarakat Miskin) adalah mengukur perubahan dari sisi pendapatan dan peluang kerja yang faktual diterima oleh masyarakat miskin.

Adapun kerangka konsep yang akan diteliti dapat dirancang sebagai berikut:

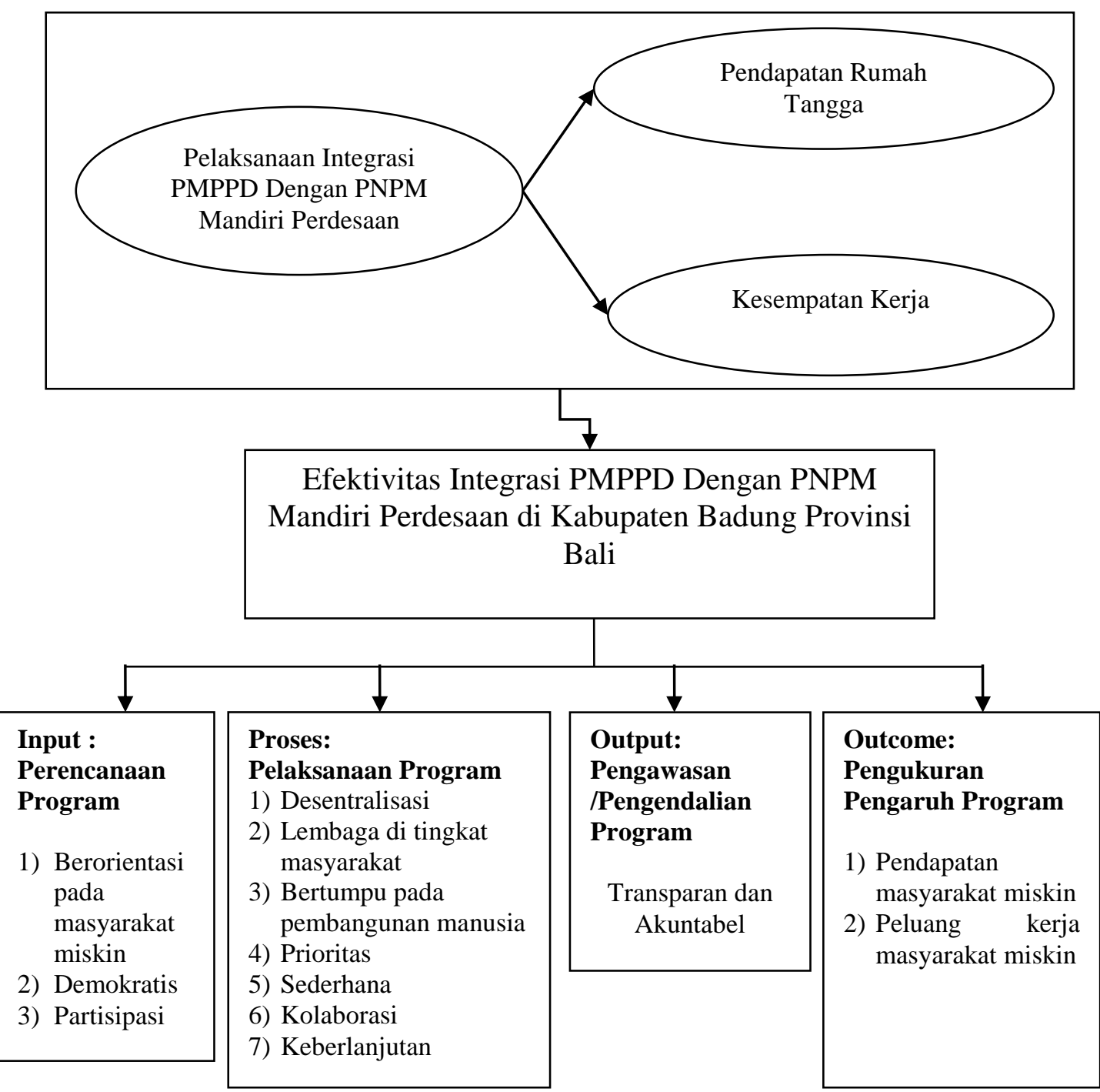

\section{Gambar 2. Kerangka Konsep}




\section{HIPOTESIS}

Hipotesis yang diajukan dikemukakan sebagai berikut:

1. Pelaksanaan integrasi Musrenbangdes dengan PNPM MPd berpengaruh terhadap Pendapatan Rumah Tangga di Kabupaten Badung

2. Pelaksanaan integrasi Musrenbangdes dengan PNPM MPd berpengaruh terhadap Kesempatan Kerja di Kabupaten Badung.

\section{HASIL PENELITIAN}

Tingkat Efektivitas Integrasi Musrenbangdes dengan PNPM MPd di Kabupaten Badung Provinsi Bali

Tingkat efektivitas integrasi Musrenbangdes dengan PNPM MPd di Kabupaten Badung Provinsi Bali akan ditentukan berdasarkan capaian persentase yang diperoleh berdasarkan kriteria standar ukuran efektivitas sebagai berikut.

Tabel 2

Standar Acuan Pengukuran Efektivitas Program

\begin{tabular}{ccc}
\hline No & Rasio Efektivitas (\%) & Ukuran Standarisasi \\
\hline 1. & Di bawah 40 & Sangat Tidak Efektif \\
2. & $40-59,99$ & Tidak Efektif \\
3. & $60-79,99$ & Cukup Efektif \\
4. & Di atas 80 & Sangat Efektif \\
\hline
\end{tabular}

Sumber : Keputusan Menpan, Deppan No.Kep./25/M/Men.Pan/2/2004

Berdasarkan hasil analisis, tingkat efektivitas integrasi Musrenbangdes dengan PNPM MPd di Kabupaten Badung Provinsi Bali dapat digambarkan sebagai berikut.

Tabel 3

Tingkat Efektivitas Integrasi Musrenbangdes dengan PNPM MPd di Kabupaten Badung Provinsi Bali

\begin{tabular}{ccccc}
\hline No & Aspek Variabel & N & $\%$ & $\begin{array}{c}\text { Kriteria } \\
\text { Efektivitas }\end{array}$ \\
\hline Kegiatan Perencanaan & $\begin{array}{l}\text { Berorientasi Pada Masyarakat } \\
\text { Miskin }\end{array}$ & 250 & $\mathbf{8 0 , 3 2}$ & Sangat Efektif
\end{tabular}




$\begin{array}{lllll}2 & \text { Demokratis } & 250 & \mathbf{8 2 , 2 0} & \text { Sangat Efektif } \\ 3 & \text { Partisipasi Perencanaan } & 250 & \mathbf{8 6 , 9 7} & \text { Sangat Efektif } \\ \text { Rata-rata } & 250 & \mathbf{8 3 , 1 6} & \text { Sangat Efektif }\end{array}$

\section{Kegiatan Pelaksanaan}

Desentralisasi/Kewenangan

1 Masyarakat Mengelol

Program Sendiri

87,70 Sangat Efektif

2 Kelembagaan Pengelola Di

2 Tingkat Masyarakat

$250 \quad \mathbf{8 8 , 6 8} \quad$ Sangat Efektif

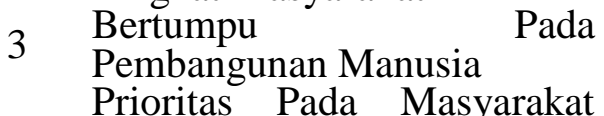

4 Miskin (Peluang Kerja

Masyarakat Miskin)

5 Sederhana

250

88,68 - Sangat Efektif

6 Kolaborasi/Keterlibatan

6 Pemerintah/Kelompok Peduli

250

85,36 Sangat Efektif

$250 \quad \mathbf{8 2 , 9 6} \quad$ Sangat Efektif

$250 \quad \mathbf{8 7 , 0 7}$

$250 \quad \mathbf{7 2 , 8 3}$

Cukup Efektif

7 Keberlanjutan

Sangat Efektif

Rata-rata

250

84,84

Sangat Efektif

\section{Kegiatan Pengawasan}

1 Transparan dan Akuntabel

250

82,99 Sangat Efektif

\section{Pengukuran Dampak Program}

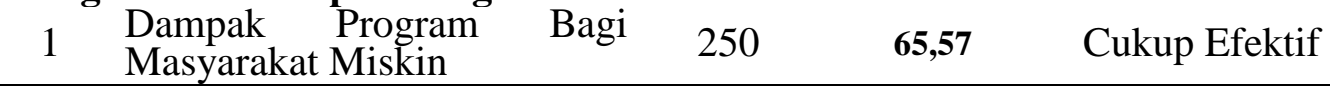

Berdasarkan Tabel 3 di atas terlihat bahwa efektivitas integrasi Musrenbangdes dengan PNPM MPd di Kabupaten Badung Provinsi Bali dapat dikatakan sangat efektif dengan nilai pencapaian di atas $80 \%$. Hal ini terlihat dari aspek variabel kegiatan perencanaan yang terdiri dari indicator (1) berorientasi pada masyarakat miskin; (2) demokratis; dan (3) partisipasi perencanaan yang secara keseluruhan ketiganya berada dalam kriteria sangat efektif. Sedangkan pada aspek variabel kegiatan perencanaan yang terdiri dari indicator (1) desentralisasi/kewenangan masyarakat mengelola program sendiri; kelembagaan pengelola di tingkat masyarakat; (3) mengacu pada pengembangan masyarakat; (4) prioritas masyarakat kurang mampu (peluang kerja masyarakat miskin); (5) sederhana; dan (6) keberlanjutan berada dalam rentang kriteria sangat 
efektif, hanya satu indikator yang berada dalam kriteria cukup efektif yaitu kolaborasi/keterlibatan pemerintah/kelompok peduli.

Selanjutnyaa pada aspek variabel kegiatan pengawasan yang diukur dengan indikator transparan dan akuntabel berada dalam kriteria sangat efektivitas. Sedangkan aspek variabel pengukuran dampak program yang diukur dengan indikator dampak program bagi masyarakat miskin berada dalam rentang cukup efektif. Hasil ini mengacu pada standar ukuran efektivitas menggunakan acuan Keputusan Menpan No.Kep./25/M/Men.Pan/2/2004, bahwa suatu program dikatakan sangat efektif apabila mencapai persentase di atas $80 \%$. Artinya secara keseluruhan integrasi Musrenbangdes dengan PNPM MPd yang diterapkan di di Kabupaten Badung Provinsi Bali telah berjalan sangat efektif. Sehingga program tersebut harus terus ditingkatkan dan terus dikembangkan guna memberikan manfaat yang lebih luas kepada masyarakat.

Dalam penelitian ini terdapat dua indikator yang berada dalam rentang cukup efektif yaitu kolaborasi/keterlibatan pemerintah/kelompok peduli dan dampak program bagi masyarakat miskin. Dari segi kolaborasi/keterlibatan pemerintah/kelompok peduli, integrasi Musrenbangdes dengan PNPM MPd di Kabupaten Badung Provinsi Bali belum dijalankan secara penuh, artinya keterlibatan dalam berbagai kegiatan belum berjalan secara menyeluruh. Sedangkan dalam aspek dampak program bagi masyarakat miskin, integrasi Musrenbangdes dengan PNPM MPd di Kabupaten Badung Provinsi Bali belum tercapai secara optimal. Peningkatan pendapatan keluarga miskin berdasarkan tabel 5.25 terlihat bahwa tingkat pendapatan keluarga miskin di Kabupaten 
Ida Bagus Krisdeny Mahajaya, I Nyoman Mahaendra Yasa, dan Ni Nyoman Yuliarmi. Efektivitas...

Badung pada kisaran 1.300.000 sampai dengan 1.800 .000 sebelum integrasi program adalah 16,40\%, mengalami kenaikan setalah integrasi program menjadi $32,80 \%$. Sedangkan pendapatan pada kisaran lebih dari 1.800 .000 sebelum integrasi program adalah 9,60\%, mengalami kenaikan setalah integrasi program menjadi $10,80 \%$.

Berdasarkan hasil tersebut terlihat bahwa terjadi peningkatan pendapatan, namun belum optimal dalam mengatasi tingkat kemiskinan. Hal ini karena tingkat pengentasan kemiskinan yang ada belum secara keseluruhan dapat di atasi. Masyarakat sebagai pelaku utama integrasi Musrenbangdes dengan PNPM MPd mulai dari tahap perencanaan, pelaksanaan hingga pelestarian. Dalam aspek dampak program bagi masyarakat miskin integrasi Musrenbangdes dengan PNPM MPd di Kabupaten Badung Provinsi Bali belum memberikan dampak yang optimal. Peningkatan pendapatan keluarga miskin terlihat bahwa tingkat pendapatan keluarga miskin di Kabupaten Badung pada kisaran 1.300.000 sampai dengan 1.800.000 sebelum integrasi program adalah 16,40\%, mengalami kenaikan setalah integrasi program menjadi $32,80 \%$. Sedangkan pendapatan pada kisaran lebih dari 1.800 .000 sebelum integrasi program adalah 9,60\%, mengalami kenaikan setalah integrasi program menjadi $10,80 \%$.

Penggunaan Bantuan Hasil Integrasi Musrenbangdes dengan PNPM MPd Oleh Masyarakat Di Kabupaten Badung 
Berdasarkan hasil penelitian diketahui bahwa penggunaan bantuan hasil integrasi Musrenbangdes dengan PNPM MPd oleh masyarakat Di Kabupaten Badung dapat dilihat sebagai berikut.

Tabel 4

Penggunaan Bantuan Hasil Integrasi Musrenbangdes dengan PNPM MPd Di Kabupaten Badung

\begin{tabular}{clcc}
\hline No & Penggunaan Bantuan Oleh Masyarakat & Frekwensi & Persentase \\
\hline 1 & Modal Usaha & 207 & 42,59 \\
2 & Kebutuhan Sehari-hari & 163 & 33,54 \\
3 & Biaya Sekolah & 55 & 11,32 \\
4 & Kesehatan & 53 & 10,91 \\
5 & Cicilan Utang & 6 & 1,23 \\
6 & Lainnya & 2 & 0,41 \\
\hline
\end{tabular}
Sumber : Data Primer, 2016.

Tabel 4 terlihat bahwa mayoritas penggunaan bantuan hasil integrasi musrenbangdes dengan PNPM Mandiri Perdesaan oleh masyarakat Di Kabupaten Badung adalah untuk modal usaha dengan perentase 42,59 persen, serta kebutuhan sehari-hari sebesar 33,54 persen. Untuk biaya sekolah sebesar 11,32 persen, untuk biaya kesehatan sebesar 10,91 persen, untuk cicilan hutang sebesar 1,23 persen dan untuk biaya lainnya sebesar 0,41 persen. Artinya bahwa tidak semuanya modal usaha yang diterima di gunakan dan di putar kembali untuk usahanya, namun sebagian digunakan untuk kebutuhan sehari-hari, biaya sekolah, kesehatan dan cicilan utang.

Pengaruh Pelaksanaan Integrasi Musrenbangdes dengan PNPM MPd terhadap Pendapatan Rumah Tangga di Kabupaten Badung

Untuk menganalisis pengaruh pelaksanaan integrasi Musrenbangdes dengan PNPM MPd terhadap pendapatan rumah tangga di Kabupaten Badung maka digunakan analisis regressi linier. Variabel dependen dalam penelitian ini 
Ida Bagus Krisdeny Mahajaya, I Nyoman Mahaendra Yasa, dan Ni Nyoman Yuliarmi. Efektivitas...

adalah pendapatan rumah tangga sasaran, dan variabel independen yaitu pelaksanaan integrasi Musrenbangdes dengan PNMPM MPd. Berdasarkan hasil penelitian dengan bantuan SPSS diperoleh Tabel 5 sebagai berikut.

Tabel 5

Analisa Regresi Pengaruh Pelaksanaan Integrasi Musrenbangdes dengan PNPM MPd terhadap Pendapatan Rumah Tangga di Kabupaten

\begin{tabular}{|c|c|c|c|c|c|c|}
\hline \\
\hline & \multirow[t]{2}{*}{ Model } & \multicolumn{2}{|c|}{$\begin{array}{l}\text { Unstandardized } \\
\text { Coefficients }\end{array}$} & \multirow{2}{*}{$\begin{array}{c}\text { Standardized } \\
\text { Coefficients } \\
\text { Beta } \\
\end{array}$} & \multirow{3}{*}{$\frac{\mathrm{t}}{\mathrm{t}}$} & \multirow{3}{*}{$\begin{array}{l}\text { Sig. } \\
.003\end{array}$} \\
\hline & & $\mathrm{B}$ & Std. Error & & & \\
\hline 1 & (Constant) & 13.041 & 4.182 & & & \\
\hline & 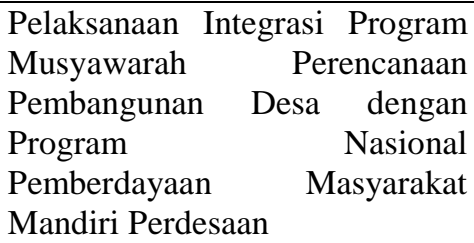 & .550 & .162 & .570 & 3.401 & .001 \\
\hline
\end{tabular}

a Dependent Variable: Pendapatan Rumah Tangga Sasaran

Tabel 5, persamaan regresi sebagai berikut:

$$
\hat{\mathrm{Y}}=13.041+0,550 \mathrm{X}
$$

Keterangan:

$\hat{Y}=$ Pendapatan Rumah Tangga Sasaran

$\mathrm{X}=$ Pelaksanaan Integrasi Program Musyawarah Perencanaan Pembangunan Desa dengan Program Nasional Pemberdayaan Masyarakat Mandiri Perdesaan

Berdasarkan persamaan tersebut terlihat bahwa nilai probabilitas signifikansi adalah 0,001 dengan nilai koefisien regresi positif 0,550 . Selain itu nilai $\mathrm{t}_{\text {hitung }}$ sebesar $3.401>\mathrm{t}_{\text {tabel }}$ sebesar 1,676 dan sig $<0,05$ maka dikatakan bahwa pelaksanaan integrasi Musrenbangdes dengan PNPM MPd berpengaruh terhadap pendapatan rumah tangga di Kabupaten Badung. Hasil ini sependapat dengan data pendapatan terendah sebelum integrasi Musrenbangdes dengan PNPM MPd seperti yang digambarkan pada Tabel 5.25 sebagai berikut:

\section{Tabel 6}

Tingkat Pendapatan Keluarga Miskin di Kabupaten Badung

\begin{tabular}{|c|c|c|c|c|c|}
\hline \multicolumn{2}{|c|}{ Sebelum Integrasi Program } & \multicolumn{3}{c|}{ Setelah Integrasi Program } \\
\hline Pendapatan keluarga & Orang & $\%$ & Pendapatan keluarga & Orang & $\%$ \\
\hline
\end{tabular}




\begin{tabular}{|c|c|c|c|c|c|}
\hline ( rupiah) & & & ( rupiah) & & \\
\hline $300.000,-<800.000,-$ & 33 & 13,20 & $400.000,-<800.000,-$ & 19 & 7,60 \\
\hline $800.000,-<1.300 .000,-$ & 152 & 60,80 & $800.000,-<1.300 .000,-$ & 122 & 48,80 \\
\hline $1.300 .000,-<1.800 .000,-$ & 41 & 16,40 & $1.300 .000,-<1.800 .000,-$ & 82 & 32,80 \\
\hline $1.800 .000,+$ & 24 & 9,60 & $1.800 .000,+$ & 27 & 10,80 \\
\hline Jumlah & 250 & 100,00 & Jumlah & 250 & $\begin{array}{c}100,0 \\
0\end{array}$ \\
\hline
\end{tabular}

Sumber : Data Primer, 2017 (diolah)

Tabel 6 terlihat bahwa pendapatan terendah sebelum integrasi Musrenbangdes dengan PNPM MPd sebesar Rp. 300.000,- dan tertinggi sebesar Rp. 1.800.000,- meningkat setelah dilakukan pendapatan terendah setelah integrasi Musrenbangdes dengan PNPM MPd sebesar Rp. 400.000,- dan tertinggi sebesar Rp. 1.800.000,-. Hasil ini memberikan gambaran bahwa integrasi Musrenbangdes dengan PNPM MPd memberikan dampak yang positif dalam meningkatkan pendapatan terendah masyarakat.

\section{Pengaruh Pelaksanaan Integrasi Musrenbangdes dengan PNPM MPd terhadap Kesempatan Kerja di Kabupaten Badung}

Untuk menganalisis pengaruh pelaksanaan integrasi Musrenbangdes dengan PNPM MPd terhadap kesempatan kerja di Kabupaten Badung maka digunakan analisis regressi linier. Variabel dependen dalam penelitian ini adalah kesempatan kerja bagi rumah tangga sasaran, dan variabel independen yaitu pelaksanaan integrasi Musrenbangdes dengan PNMPM MPd. Berdasarkan hasil penelitian dengan bantuan SPSS diperoleh Tabel 7 sebagai berikut.

Tabel 7

Analisa Regresi Pengaruh Pelaksanaan Integrasi Musrenbangdes dengan PNPM MPd terhadap Kesempatan Kerja di Kabupaten Badung

\begin{tabular}{|c|l|r|r|r|r|r|}
\hline \multirow{2}{*}{\multicolumn{2}{c|}{ Model }} & \multicolumn{2}{|c|}{$\begin{array}{c}\text { Unstandardized } \\
\text { Coefficients }\end{array}$} & $\begin{array}{c}\text { Standardized } \\
\text { Coefficients }\end{array}$ & $\mathrm{t}$ & Sig. \\
\cline { 2 - 7 } & & B & Std. Error & Beta & & \\
\hline 1 & (Constant) & 9.271 & 1.883 & & 4.409 & .000 \\
\hline
\end{tabular}




\begin{tabular}{|l|l|l|l|l|l|}
\hline $\begin{array}{l}\text { Pelaksanaan Integrasi Program } \\
\text { Musyawarah Perencanaan } \\
\text { Pembangunan Desa dengan }\end{array}$ & .422 & .174 & .863 & 6.999 & .000 \\
$\begin{array}{l}\text { Program Nasional Pemberdayaan } \\
\text { Masyarakat Mandiri Perdesaan }\end{array}$ & & & & & \\
\hline
\end{tabular}

a Dependent Variable: Kesempatan Kerja Bagi Rumah Tangga Sasaran

Berdasarkan Tabel 7, persamaan regresi sebagai berikut:

$\hat{\mathrm{Y}}=9.271+0,422 \mathrm{X}$

Keterangan:

$\hat{Y}=$ Kesempatan Kerja Bagi Rumah Tangga Sasaran

$\mathrm{X}=$ Pelaksanaan Integrasi Program Musyawarah Perencanaan Pembangunan Desa dengan Program Nasional Pemberdayaan Masyarakat Mandiri Perdesaan

Berdasarkan persamaan tersebut terlihat bahwa nilai probabilitas signifikansi adalah 0,000 dengan nilai koefisien regresi positif 0,422. Selain itu diperoleh nilai $\mathrm{t}_{\text {hitung }}$ sebesar $6.999>\mathrm{t}_{\text {tabel }}$ sebesar 1,676. Karena sig $<0,05$ dan nilai t-hitung > dari t-tabel maka dikatakan bahwa pelaksanaan integrasi Musrenbangdes dengan PNPM MPd berpengaruh terhadap kesempatan kerja di Kabupaten Badung. Hasil ini sependapat dengan data peluang kerja terendah sebelum dan sesuadah integrasi Musrenbangdes dengan PNPM MPd sebanyak 1 kali/kegiatan dan tertinggi sebanyak 6 kali/kegiatan seperti dalam Tabel 8.

Tabel 8

Tingkat Peluang Kerja Keluarga Miskin di Kabupaten Badung

\begin{tabular}{|c|c|c|c|c|c|}
\hline \multicolumn{2}{|c|}{ Sebelum Integrasi Program } & \multicolumn{3}{c|}{ Setelah Integrasi Program } \\
\hline Peluang kerja keluarga & Orang & $\%$ & Peluang kerja keluarga & Orang & $\%$ \\
\hline 1 kali/kegiatan & 17 & 6,80 & 1 kali/kegiatan & 10 & 4,00 \\
\hline 2 kali/kegiatan & 78 & 31,20 & 2 kali/kegiatan & 42 & 16,80 \\
\hline 3 kali/kegiatan & 91 & 36,40 & 3 kali/kegiatan & 78 & 31,20 \\
\hline 4 kali/kegiatan & 41 & 16,40 & 4 kali/kegiatan & 85 & 34,00 \\
\hline 5 kali/kegiatab & 16 & 6,40 & 5 kali/kegiatab & 22 & 8,80 \\
\hline 6 kali/kegiatan & 7 & 2,80 & 6 kali/kegiatan & 13 & 5,20 \\
\hline Jumlah & 250 & 100,00 & Jumlah & 250 & 100,00 \\
\hline
\end{tabular}

Sumber : Data primer, 2017 (diolah)

\section{PEMBAHASAN}




\section{Tingkat Efektivitas Integrasi Musrenbangdes dengan PNPM MPd di Kabupaten Badung Provinsi Bali}

Berdasarkan hasil analisis terlihat bahwa efektivitas integrasi Musrenbangdes dengan PNPM MPd di Kabupaten Badung Provinsi Bali dapat dikatakan sangat efektif dengan nilai pencapaian di atas $80 \%$. Hasil ini mengacu pada standar ukuran efektivitas dari Menpan No.Kep./25/M/Men.Pan/2/2004, bahwa suatu program dikatakan sangat efektif apabila mencapai persentase di atas 80\%. Artinya secara keseluruhan integrasi Musrenbangdes dengan PNPM MPd yang diterapkan di di Kabupaten Badung Provinsi Bali telah berjalan sangat efektif. Sehingga program tersebut harus terus ditingkatkan dan terus dikembangkan guna memberikan manfaat yang lebih luas kepada masyarakat. Adapun hasil efektivitas integrasi Musrenbangdes dengan PNPM MPd di Kabupaten Badung Provinsi Bali dapat dirinci sebagai berikut:

1) Tingkat Efektivitas pada Tahap Perencanaan Program

Tingkat efektivitas integrasi program pada tahap perencanaan program berada dalam rentang kategori sangat efektif. Ini menjelaskan bahwa penetapan sasaran program telah di ketahui dan disepakati seluruh masyarakat dengan mendudukan masyarakat miskin sebagai agenda utama sasaran program dan melibatkan masyarakat miskin secara aktif dengan memberikan ruang yang sangat luas untuk menyampaikan aspirasi dan terlibat di pengambilan keputusan dalam setiap proses perencanaan yang dilakukan. Akan tertapi masih terdapat beberapa kendala yaitu usulan kegiatan bedah rumah bagi masyarakat miskin belum terakomodir untuk seluruh masyarakat miskin karena terbatasnya alokasi dana. Dan terkait dengan alokasi dana ini, 
masih di alokasikan per banjar berdasarkan dengan prioritas banjar yang memiliki masyarakat miskin terbanyak.

2) Tingkat Efektivitas pada Tahap Pelaksanaan Program

Tingkat efektivitas integrasi program pada tahap pelaksanaan program berada dalam rentang kategori sangat efektif. Hal ini menunjukkan bahwa pelaksanaan program dijalankan sesuai rencana dan telah dikelola secara mandiri oleh masyarakat miskin melalui kelembagaan yang dapat dipercaya, aspiratif dan representatif yang bertumpu pada penguatan SDM dan penguatan aktifitas sosial dalam setiap proses pelaksanaan kegiatan mempertimbangkan sistem pelestariannya sebagai keberlanjutan program. Pelaksanaan kegiatan juga mengajak masyarakat secara gotong royong dan hampir semua kelompok masyarakat miskin mendapatkan manfaat dari setiap proyek karena mendapatkan upah tambahan. Dana bergulir untuk kelompok masyarakat miskin juga telah berjalan dan bergulir tiga kali saat penelitian ini dilakukan. Namun demikian, terbatasnya dana khususnya bersumber dari pemerintah daerah tidak menjangkau seluruh KK masyarakat miskin sebagai penerima manfaat, sedangkan alokasi simpan pinjam ini yang bersumber dari PNPM MPd hanya dapat berfungsi sebagai stimulant belum banyak di rasakan dan tidak terlalu cepat berkembang.

3) Tingkat Efektivitas pada tahap Pengawasan/Pengendalian Program

Tingkat efektivitas integrasi program pada tahap pengawasan program (output) berada dalam rentang kategori sangat efektif. Ini ditunjukkan dari komponen transparansi dan akuntabel. Dua indikator dari komponen 
transparansi dan akuntabel menunjukkan sangat efektive yaitu terdapat kegiatan evaluasi dan monitoring pemeriksaan keuangan secara independen dan masyarakat dapat memperoleh seluruh informasi secara terbuka.

\section{Pengaruh Pelaksanaan Integrasi Musrenbangdes dengan PNPM MPd terhadap Pendapatan Rumah Tangga di Kabupaten Badung}

Pelaksanaan efektivitas integrasi Musrenbangdes dengan PNPM MPd di Kabupaten Badung berpengaruh terhadap pendapatan rumah tangga di Kabupaten Badung. Artinya program yang dilaksanakan dapat memberikan dampak positif bagi pendapatan Rumah Tangga Sasaran di Kabupaten Badung Provinsi Bali. Musrenbang merupakan forum perencanaan pembangunan formal dari tingkatan yang diawali dari desa, kecamatan, kabupaten, provinsi sampai dengan nasional yang bertujuan mengsinkronisasi aspirasi masyarakat dalam perencanaan pembangunan pemerintah. Kabupaten Badung turut menerapkan kebijakan pemerintah, salah satunya kebijakan yang berkaitan dengan kesejahteraan masyarakat. Integrasi Musrenbangdes dengan PNPM MPd di Kabupaten Badung dengan masing-masing rumah tangga sasaran yang sangat rentan jatuh ke bawah garis kemiskinan. Dengan menggunakan pendekatan pengentasan kemiskinan dengan melibatkan masyarakat (Integrasi Musrenbangdes dengan PNPM MPd) dengan rumusan menyatukan perencanaan yang melibatkan masyarakat yang bersifat partisipatif, mendampingi masyarakat desa agar mampu memiliki program jangka menengah desa dan mengendalikan pelaksanan program pembangunan, sehingga sasaran program agar masyarakat tidak jatuh di bawah garis kemiskinan. 
Ida Bagus Krisdeny Mahajaya, I Nyoman Mahaendra Yasa, dan Ni Nyoman Yuliarmi. Efektivitas...

Pengaruh Pelaksanaan Integrasi Musrenbangdes dengan PNPM MPd terhadap Kesempatan Kerja di Kabupaten Badung

Berdasarkan hasil analisis terlihat bahwa pelaksanaan integrasi Musrenbangdes dengan PNPM MPd berpengaruh terhadap kesempatan kerja di Kabupaten Badung. Masalah ketenagakerjaan berhubungan sangat erat dengan kemiskinan semakin sedikit lapangan pekerjaan yang tersedia akan meningkatkan jumlah pengangguran yang pada akhirnya mengakibatkan semakin banyak penduduk yang jatuh ke bawah garis kemiskinan. Penyediaan lapangan pekerjaan yang sesuai dengan karakteristik penduduk miskin merupakan upaya terobosan yang di rasa akan jauh lebih efektif dalam mengentaskan kemiskinan jika dibandingkan dengan berbagai program pemberian bantuan sosial, terutama jika ditinjau dari aspek keberlanjutannya. Pengintegrasian PNPM Mandiri Perdesaan dengan musyawarah perencanaan pembangunan desa baik secara musyarah kemasyarakatan maupun secara kegiatan politik.

\section{SIMPULAN DAN SARAN}

\section{Simpulan}

Kesimpulan dalam penelitian ini dapat diuraikan secara rinci sebagai berikut:

1) Tingkat efektivitas integrasi program musyawarah perencanaan pembangunan desa dengan program nasional pemberdayaan masyarakat mandiri perdesaan di Kabupaten Badung Provinsi Bali dapat dikatakan sangat efektif dengan nilai pencapaian di atas $80 \%$. Artinya secara keseluruhan integrasi program musyawarah perencanaan pembangunan desa dengan program nasional pemberdayaan masyarakat mandiri perdesaan yang diterapkan di Kabupaten 
Badung Provinsi Bali telah berjalan sangat efektif. Sehingga program tersebut harus terus ditingkatkan dan terus dikembangkan guna memberikan manfaat yang lebih luas kepada masyarakat.

2) Pelaksanaan integrasi program musyawarah perencanaan pembangunan desa dengan program nasional pemberdayaan masyarakat mandiri perdesaan berpengaruh positif dan signifikan terhadap pendapatan rumah tangga sasaran di Kabupaten Badung Provinsi Bali. Artinya dengann adanya program ini pendapatan rumah tangga sasaran dapat meningkat sesuai dengan tujuan program yang ingin dicapai.

3) Pelaksanaan integrasi program musyawarah perencanaan pembangunan desa dengan program nasional pemberdayaan masyarakat mandiri perdesaan berpengaruh positif dan signifikan terhadap kesempatan kerja bagi rumah tangga sasaran di Kabupaten Badung Provinsi Bali. Artinya dengan adanya program musyawarah perencanaan pembangunan desa dengan program nasional pemberdayaan masyarakat mandiri perdesaan, maka kesempatan kerja bagi rumah tangga sasaran dapat terbuka lebih luas, sehingga kesempatan bekerja mereka makin banyak tersedia.

\section{Saran}

Adapun beberapa saran diungkapkan berikut:

1) Berdasarkan hasil penelitian terlihat bahwa pada aspek kolaborasi/keterlibatan pemerintah/kelompok peduli dan dampak program bagi masyarakat miskin masuk dalam kategori cukup efektif. Artinya tingkat efektivitas integrasi program Musrenbangdes dengan PNPM MPd harus terus 
ditingkatkan agar program yang dilaksanakan dapat lebih memberikan manfaat secara luas terhadap masyarakat miskin.

2) Masyarakat sebagai kelompok sasaran dari program PNPM-Mandiri Pedesaan, diharapkan berperan aktif dalam pelaksanaan kegiatan. Karena pada dasarnya tujuan dari PNPM-MP adalah untuk meningkatkan taraf hidup masyarakat setempat.

3) Pinjaman bergulir membantu masyarakat dalam menjalankan usahanya, namun dalam pelaksanaannya tetap harus dievaluasi dari aspek kegunaan dan keberlanjutannya.

4) Hendaknya unit pengeola keuangan memberikan ketegasan kepada anggota pinjaman bergulir dalam hal penggunaannya, sehingga fokus penggunaan dana tersebut adalah untuk modal usaha, bukan untuk keperluan yang lainnya.

\section{DAFTAR PUSTAKA}

Darto. 2014. "Perilaku Aparat Desa Dalam Perspektif Otonomi Daerah VDI Kabupaten Kuningan Provinsi Jawa Barat". Majalah Ilmiah UNIKOM. Vol. 14. No. 1.

Katuhu, Octavianus. 2014. "Evaluasi Kebijakan Program Nasional Pemberdayaan Masyarakat Mandiri Pedesaan (PNPM-MD) di Kecamatan Siau Timur". Jurnal Akuntansi. Vol. 1. No. 1.

Sukirno, S. 2004. Ekonomi Pembangunan: Proses, Masalah dan Dasar Kebijakan. Jakarta: Bina Grafika.

Subagyo. 2000. Efektivitas Penanggulangan Kemiskinan dalam Pemberdayaan Masyarakat Perdesaan : Studi Kasus di Kabupaten Kediri Jawa Timur (tesis). Yogyakarta: Universitas Gajah Mada.

Susilo, Anggun Trisnanto Hari. 2012. "The Indonesian National Program For Community Empowerment (PNPM)-Rural: Decentralization In The Context Of Neoliberalism And World Bank Policies". International Institute of Social Studies. Vol. 2. No. 1. 